\title{
Alternative method of patch implantation and creation for postinfarction ventricular septal defect repair by the infarct exclusion technique
}

\author{
Masashi Komeda, MD, PhD, Daito, Japan
}

\author{
From the Department of Cardiovascular Surgery, Jinsenkai Hospital, Daito, Osaka, Japan. \\ Disclosures: Author has nothing to disclose with regard to commercial support. \\ Received for publication July 29, 2016; revisions received Aug 11, 2016; accepted for publication Sept 2, 2016; \\ available ahead of print Oct 14, 2016. \\ Address for reprints: Masashi Komeda, MD, PhD, Department of Cardiovascular Surgery, Jinsenkai Hospital, 8- \\ 2-22 Morofuku, Daito, Osaka 574-0044, Japan (E-mail: zeek-m@bf7.so-net.ne.jp). \\ J Thorac Cardiovasc Surg 2017;153:91-3 \\ $0022-5223 / \$ 36.00$ \\ Copyright (C) 2016 by The American Association for Thoracic Surgery \\ http://dx.doi.org/10.1016/j.jtcvs.2016.09.020
}

Video clip is available online.

Postinfarction ventricular septal defect (VSD) is surgically challenging and carries a high operative mortality. ${ }^{1}$ Catheter interventions, including Amplatzer occluder (St Jude Medical Inc, St Paul, Minn) ${ }^{2}$ and circulatory assist, have been used in selected patients; however, postinfarction VSD remains a surgical emergency.

Surgical outcomes are often poor because of (1) poor preoperative cardiac and general condition, (2) technical difficulties associated with the surgical treatment of a rare condition $^{1}$ and difficult maneuvers in narrow ventricular cavity, and (3) a condition of the myocardium shortly after infarction that does not favor early surgery. We used a modified infarct exclusion technique ${ }^{3,4}$ designed to overcome technical difficulties and myocardial fragility.

\section{CLINICAL SUMMARY}

A 68-year-old woman was transferred to our hospital because of cardiogenic shock. She had chest pain and shortness of breath for 5 hours before the admission. Echocardiography showed aneurysmal dilatation of left ventricular apex, left-to-right shunt at the anterior interventricular septum, and moderate tricuspid regurgitation. The VSD was $8 \mathrm{~mm}$ in diameter. Her left ventricular diastolic diameter was $43 \mathrm{~mm}$, her ejection fraction was $50 \%$, her estimated right ventricular pressure was $40 \mathrm{~mm} \mathrm{Hg}$, and her inferior vena cava measured 18 to $14 \mathrm{~mm}$ with intra-aortic balloon pump support. Blood and serum testing revealed the following: creatine kinase, $280 \mathrm{U} / \mathrm{L}$; aspartate aminotransferase, $1777 \mathrm{U} / \mathrm{L}$; total bilirubin, $3.02 \mathrm{mg} / \mathrm{dL}$; creatinine, 1.14 ; C-reactive protein, $7.48 \mathrm{mg} / \mathrm{L}$; creatine kinase isoenzyme $\mathrm{MB}, 16 \mathrm{ng} / \mathrm{mL}$; troponin T, $12.558 \mathrm{ng} / \mathrm{mL}$; B-type natriuretic peptide, $>2000 \mathrm{pg} / \mathrm{mL}$; and hematocrit, $34.1 \%$. technique.

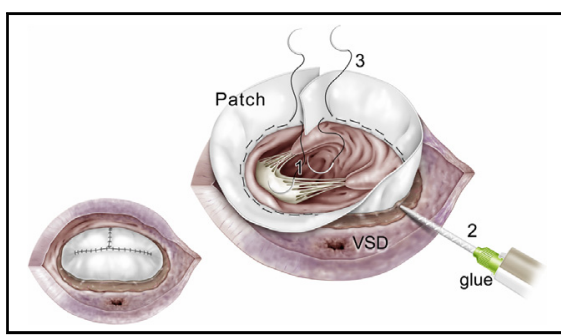

Easier and more reliable exclusion for postinfarction ventricular septal defect.

Central Message

This is the first report of a modified technique for postinfarction ventricular septal defect. It is much easier than traditional exclusion methods. Let us hope that it can help improve the surgical outcome.

See Editorial Commentary page 93.

Her electrocardiogram showed normal sinus rhythm with complete left bundle branch block. Chest radiography disclosed cardiomegaly with pulmonary congestion. A coronary angiogram revealed $75 \%$ left main coronary artery, $99 \%$ left anterior descending coronary artery, and $75 \%$ left circumflex coronary artery stenoses.

Surgery was delayed until day 2 after admission because of the clopidogrel sulfate medication. During surgery, the left ventricle was opened $2 \mathrm{~cm}$ from the left anterior descending coronary artery toward the apex (Figure 1). The anterior septum and anterior left ventricular wall were infarcted, and a VSD was found in the midventricular septum. We decided to use a modified infarct exclusion

The border of the healthy and infarcted myocardium was marked with a blue stain (Video 1). A strip of bovine pericardial patch was sewn to the blue line with 4-0 polypropylene continuous horizontal-mattress sutures in a fashion similar to the Fontan stitch for the Dor procedure (circumferential needle work parallel to the suture line; Figure 2). After completion of the first suture layer, BioGlue (CryoLife Inc, Kennesaw, Ga) was applied to the suture line area on the mural side. When the glue and the adjacent myocardium hardened, another horizontal mattress suture was placed from the left ventricular chamber side just parallel to the first layer. After completion of 


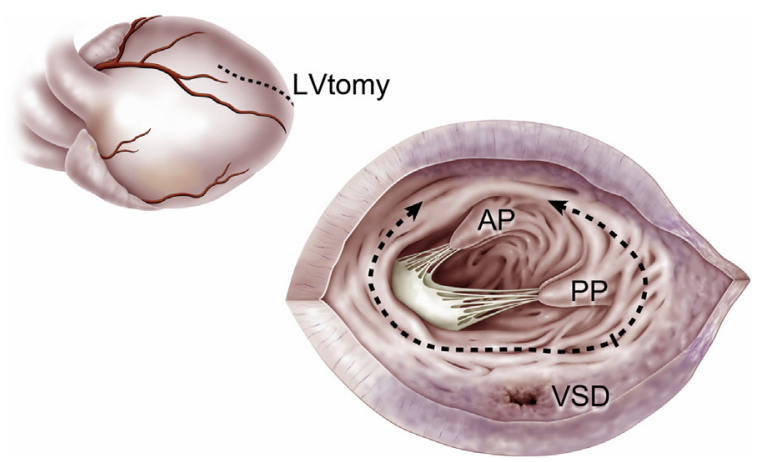

FIGURE 1. The ventricular septal defect (VSD) and the suture line, as seen through the left ventriculotomy (LVtomy). The left panel shows the location of the left ventriculotomy (dashed line), and the right panel shows the suture line (dashed line with arrows). Note that suture line is away from the infarcted left ventricular area, which is depicted in shadow. The more proximal the postinfarction ventricular septal defect is, the longer the left ventriculotomy will be. The farther the suture line is from the postinfarction ventricular septal defect or infarction, the more stable the suture line will be. $A P$, Anterior papillary muscle; $P P$, posterior papillary muscle.

the second suture line, the patch was completed with 4-0 polypropylene sutures to produce a dome shape and the left ventriculotomy was closed. The patient received a left internal thoracic artery graft to the left anterior descending coronary artery. She was separated from cardiopulmonary bypass with support from an intra-aortic balloon pump and a small dose of inotropic agent. The crossclamp time was 118 minutes; the cardiopulmonary bypass time was 164 minutes.

The patient's postoperative course was uneventful except that her rehabilitation time was longer than usual; she was discharged as an ambulatory patient 40 days

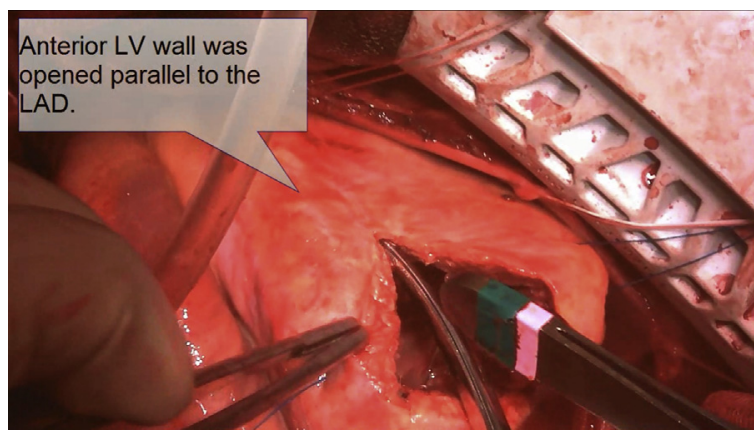

VIDEO 1. Surgery for postinfarction ventricular septal defect by a modified technique of infarct exclusion in a 68-year-old woman. $C C$, Chief complaint; $P I$, present illness; $M I$, myocardial infarction; $P E$, physical examination; $B P$, blood pressure; $P A P$, pulmonary artery pressure; $I A B P$, intra-aortic balloon pump; VSP, ventricular septal perforation (postinfarct ventricular septal defect); $L V D d$, left ventricular end-diastolic diameter; $E F$, ejection fraction; $L V$, left ventricular; $L A D$, left anterior descending coronary artery; LVtomy, left ventriculotomy; $A P$, anterolateral papillary muscle; $P P$, posteromedial papillary muscle; $P O D$, postoperative day; $D / C$, discharged. Video available at: http://www.jtcvsonline.org/article/ S0022-5223(16)31138-2/addons.

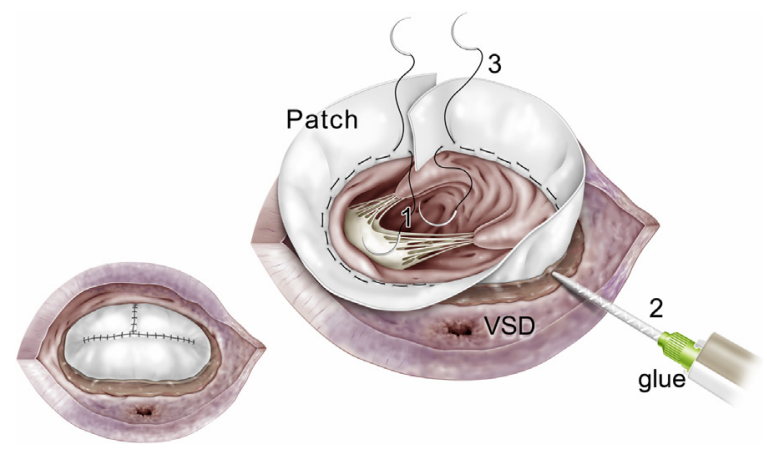

FIGURE 2. The pericardial patch during and after the procedures. The right panel illustrates the first suture line (1), the glue application (2), and the second suture line (3). The left lower panel shows the completed patch. Horizontal mattress sutures make it easier to work deep in the narrow left ventricular cavity than is possible with over and over running sutures. There is also less tearing of the myocardium. Note that the glue was applied on the side of the postinfarction ventricular septal defect (VSD) to avoid damage to the mitral valve. The patch dome is slightly higher than the inner surface of the left ventriculotomy to reduce stress to the suture lines so that residual or recurrent shunt can be prevented.

postoperatively. Postoperative echocardiography at the outpatient clinic showed no VSD shunting and mild-tomoderate mitral and tricuspid regurgitation. Six months postoperatively, she is in New York Heart Association functional class II and doing well.

\section{DISCUSSION}

There are 4 differences between this "modified" technique and the traditional technique. ${ }^{3,4}$ First, the former uses horizontal mattress sutures rather than running sutures. It is helpful for working with large needles within the narrow left ventricular cavity and keeping away from the fragile myocardium surrounding the VSD or infarct area. Second, it uses BioGlue, which renders the fragile myocardium stiffer and easier to suture. Third, it completes patch assembly after the sewing, whereas the latter creates a patch dome during the sewing. In the modified technique, the operator can focus entirely on sewing without concerns about 3-dimensional patch shape. Fourth, the modified technique creates a dome that is slightly raised relative to the inner surface of the left ventriculotomy, whereas the traditional technique does not. Finite element analysis reveals that raised-dome patches decrease the stress on the suture line. ${ }^{5}$ For these reasons, we believe that the patch suture line has increased stability.

The operation seems reproducible in our wet laboratory practice and simulation. In fact, the operation in the case presented here was performed by a relatively inexperienced surgeon. Because the surgery does not damage the right ventricle and interventricular septum, it can potentially minimize postoperative right ventricular failure. Because of the infarct exclusion nature of the surgery, 
this modified method may help prevent late left ventricular remodeling.

This method may allow surgery in patients with hyperacute phase illness. It may help prevent pneumonia or multiorgan failure in patients awaiting surgery. Further investigations are warranted.

\section{References}

1. Arnaoutakis GJ, Zhao Y, George TJ, Sciortino CM, McCarthy PM, Conte JV. Surgical repair of ventricular septal defect after myocardial infarction: outcomes from the Society of Thoracic Surgeons National Database. Ann Thorac Surg. 2012;94: 436-43; discussion 443-4.
2. Dawson AG, Williams SG, Cole D. Does the placement of an Amplatzer septal occluder device confer benefit in patients with a post-infarction ventricular septal defect? Interact Cardiovasc Thorac Surg. 2014;19: 1040-7.

3. Komeda M, Fremes SE, David TE. Surgical repair of postinfarction ventricular septal defect. Circulation. 1990;82(5 Suppl):IV243-7.

4. David TE, Dale L, Sun Z. Postinfarction ventricular septal rupture: repair by endocardial patch with infarct exclusion. J Thorac Cardiovasc Surg. 1995;110: 1315-22.

5. Ito T, Hagiwara H, Maekawa A, Yamazaki T. Finite element analysis regarding patch size, stiffness, and contact condition to the endocardium in surgery for post infarction ventricular septal rupture. Gen Thorac Cardiovasc Surg. 2013; 61:632-9. (Komeda M. Editorial comments. Gen Thorac Cardiovasc Surg. 2013;61:612-3.)

\title{
EDITORIAL COMMENTARY
}

\section{Surgery for postinfarction ventricular septal rupture}

\author{
Tirone E. David, MD
}

\footnotetext{
From the Division of Cardiac Surgery, Peter Munk Cardiac Centre, Toronto General Hospital and University of Toronto, Toronto, Ontario, Canada.

Disclosures: Author has nothing to disclose with regard to commercial support.

Received for publication Sept 13, 2016; accepted for publication Sept 14, 2016; available ahead of print Oct 6, 2016.

Address for reprints: Tirone E. David, MD, 200 Elizabeth St 4N453, Toronto, Ontario, Canada M5G 2C4 (E-mail: tirone.david@uhn.ca).

J Thorac Cardiovasc Surg 2017;153:93-4

0022-5223/\$36.00

Copyright (C) 2016 by The American Association for Thoracic Surgery

http://dx.doi.org/10.1016/j.jtcvs.2016.09.021
}

Dr Komeda has described an useful modification of the infarct exclusion technique to treat left ventricular septal rupture following an acute myocardial infarction. ${ }^{1}$ Instead of using a preshaped patch of glutaraldehyde-fixed bovine pericardium that excludes the infarcted septum by suturing it to the healthy myocardium all around with a simple running suture taking deep bites, as we described more than 2 decades ago, ${ }^{2}$ the author used a large strip of patch and secured it to the healthy septum with a double layer of continuous horizontal mattress sutures, applied Bio-Glue (Cryolife, Kennesaw, Ga) in between the layers, and then tailored the patch to exclude the left ventricular cavity from the infarct. The patient did well, and demonstrated no recurrent defect 6 months later. This modification is probably useful for surgeons who have to manage this type of mechanical complication of myocardial infarction.

Rupture of the ventricular septum following acute myocardial infarction has become a rare disorder in North America. During a 7-year period starting in 1987, we operated on 45 patients with acute septal rupture, ${ }^{2}$ whereas in the most recent 7 year period we had only 9 patients. A report based on the

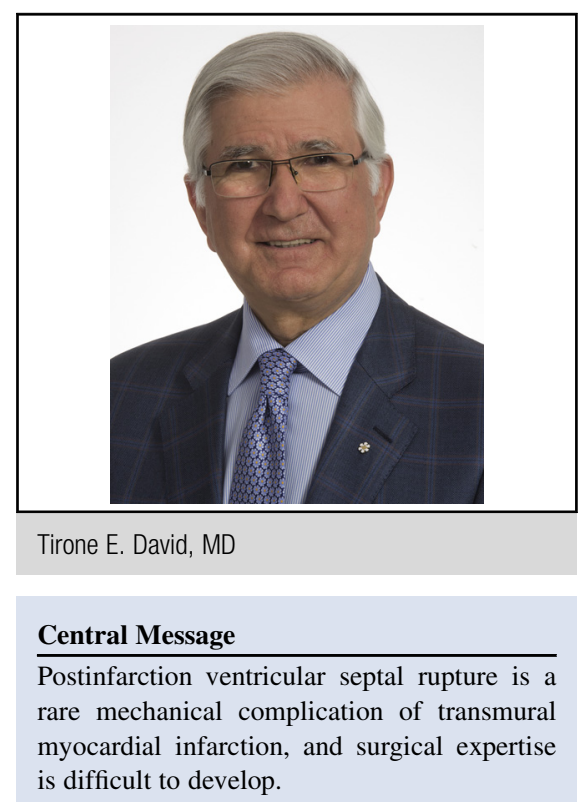

See Article page 91.

Society of Thoracic Surgeons Database for 1999 to 2010 noted that approximately 232 to 297 operations were performed per year in a total of 666 cardiac units surveyed. ${ }^{3}$ It is very difficult to teach operative techniques when the disease is so uncommon and its surgical treatment is often disappointing. ${ }^{3}$ In addition, anterior septal wall ruptures are often associated with extensive necrosis of the left ventricle and relatively minor necrosis of the right ventricle, whereas posterior ruptures involve 